\title{
Visualizing thermal comfort in residential passive house designs
}

Katerina Vrotsou and Wiktoria Glad

The self-archived postprint version of this journal article is available at Linköping University Institutional Repository (DiVA):

http:// urn.kb.se/ resolve?urn=urn:nbn:se:liu:diva-177475

N.B.: When citing this work, cite the original publication.

Vrotsou, K., Glad, W., (2021), Visualizing thermal comfort in residential passive house designs, \&lt; em\&gt; Proceedings of the Twelfth ACM International Conference on Future Energy Systems (e-Energy '21). Association for Computing Machinery, New York, NY, USA, 412-416.

https:// doi.org/ 10.1145/3447555.3466605

Original publication available at:

https:// doi.org/ 10.1145/3447555.3466605

Copyright:

https:// www.acm.org/ 


\section{Visualizing thermal comfort in residential passive house designs}

\author{
Katerina Vrotsou \\ Department of Science and Technology \\ Linköping University, Sweden \\ katerina.vrotsou@liu.se
}

\author{
Wiktoria Glad \\ Department of Thematic Studies \\ Technology and Social Change \\ Linköping University, Sweden
}

\begin{abstract}
Energy use for thermal comfort in housing accounts for a large share of total energy use in many countries. The housing sector has the potential to lower the demand for heating and cooling through better building designs, such as the passive house concept. This concept integrates building technologies, energy systems and activities performed by end-users in their everyday lives to minimise the use of external energy sources for thermal comfort. In this study we propose a methodology based on the combination of personal diary data and their in-context interactive visualization as a promising approach to study and better understand thermal comfort in private spheres. We collected activity diaries from residents in a new display city district called Vallastaden in Linköping, Sweden. Passive house designs were promoted in Vallastaden and around 10 percent of the new housing was built with this concept. Activity and thermal comfort data from the diaries were digitalised and coded. Following this the data were represented and visually explored using an adapted, for the purpose, version of a visual analysis tool.
\end{abstract}

\section{CCS CONCEPTS}

- Human-centered computing $\rightarrow$ Visualization; • Applied computing $\rightarrow$ Computers in other domains.

\section{KEYWORDS}

Thermal comfort, time geography, time diaries, visualization

\section{ACM Reference Format:}

Katerina Vrotsou and Wiktoria Glad. 2021. Visualizing thermal comfort in residential passive house designs. In The Twelfth ACM International Conference on Future Energy Systems (e-Energy '21), June 28-7uly 2, 2021, Virtual Event, Italy. ACM, New York, NY, USA, 5 pages. https://doi.org/10.1145/ 3447555.3466605

\section{INTRODUCTION}

In light of the current unsustainable use of limited resources and climate change issues, there is an urgent call for novel designs of products and services that can fulfil our needs without doing harm to the environment. Housing is an example of a basic human need that cannot be compromised, but that in many cases could be designed more sustainable. To this end, passive houses have been

Permission to make digital or hard copies of all or part of this work for personal or classroom use is granted without fee provided that copies are not made or distributed for profit or commercial advantage and that copies bear this notice and the full citation on the first page. Copyrights for components of this work owned by others than the author(s) must be honored. Abstracting with credit is permitted. To copy otherwise, or republish, to post on servers or to redistribute to lists, requires prior specific permission and/or a fee. Request permissions from permissions@acm.org.

e-Energy '21, June 28-July 2, 2021, Virtual Event, Italy

(c) 2021 Copyright held by the owner/author(s). Publication rights licensed to ACM ACM ISBN 978-1-4503-8333-2/21/06 . \$ \$15.00

https://doi.org/10.1145/3447555.3466605 proposed as a promising sustainable and affordable direction. A passive house is a low energy building concept designed to minimise heat losses from a building, making use of internal heat sources, passive solar radiance and keeping external heat sources to a minimum [11]. As in conventional buildings, the interaction between humans, the building envelop and the heating and ventilation systems are key to achieve good thermal comfort for the users of the building. In passive houses humans are even more important since people's domestic practices and internal heat sources contribute with a larger share of the heat balance of the building [27]. Previous research has stressed the variety of users' perception of thermal comfort in passive houses and the need to continue to focus on the end users in housing [19]. The interaction between everyday activities and the heating system is key to develop our understanding of thermal comfort in passive houses. Users of passive houses also witness about better indoor climate when the design of the building itself, with careful planning of building orientation in regards to cardinal directions, window placements and the heating and ventilation systems, are better in tune with everyday practices at home $[12,19]$. To understand thermal comfort, Shove [28], Isaksson [19], Gram-Hansen [14] propose asking individuals about their thermal comfort instead of trying to measure something that is experienced differently by every individual and is tightly connected to everyday activities performed differently in all households.

In this paper we present an interdisciplinary approach to researching users' experiences of and activities for achieving thermal comfort in the display neighbourhood Vallastaden in southeast Sweden comprising housing units designed as passive houses. Our contribution lies in the qualitative research on thermal comfort that stresses the importance of considering residents individual variations. Our goal is to make such variations visible and enable an interactive multi-faceted exploration of the data to study the contexts in which they appear, i.e. during different domestic daily activities. To this end, we conducted a study with personal activity diary collections during different seasons and visually explore the results with the aim to describe and analyse experienced thermal comfort. We propose that the combination of an information-rich data source such as activity diaries with an interactive in-context visualization provide a powerful method to study and better understand thermal comfort in private spheres.

\section{BACKGROUND - VALLASTADEN}

In Sweden, the market for passive houses has grown since energy efficiency is on the political agendas and awareness has increased of how decreased negative environmental impact can be harmonised with lower heating costs. So, when Vallastaden was planned by the Linköping municipality in 2012-2016, passive houses were part of their vision for a sustainable neighbourhood that would be a role model for future city district developments. 
Developers who pledged to build passive houses would more likely be offered land in the new city district, but there was a general requirement for all developers to reach 25 percent better energy performance than stated in the mandatory Swedish building code. Energy issues were generally part of the vision for Vallastaden and the municipal energy company Tekniska verken provided new infrastructure of what they promote as an innovative culvert design In this case the culvert is an underground concrete tunnel carrying pipes for district heating. With the provision of energy services in place, the requirement on developers to reach better energy performance than the building code and some developers pledging to build with passive designs, questions arose about how residents perceive these features as part of their everyday lives and activities. These questions became a focus of our research project, targeting thermal comfort in Vallastaden passive housing. Verification of the energy class of the houses is still ongoing, but so far only three housing units have reached passive house class.

\section{RELATED WORK}

A common approach to studying thermal comfort in indoor environments focuses primarily on modelling it based on measured data relating to air flow, temperature, humidity [5]. There are several standards that have been established over the years and several tools have been created for the visualization of thermal comfort relating to these values [5, 23, 24, 26, 30].

Research has however shown that the residents' experience of thermal comfort is an equally important factor to consider, which as noted previously, is especially true in the case of passive housing where residents' domestic activities and internal heat sources have a larger effect on the heat balance of the building [27]. As such, the use of questionnaires and/or interviews has been proposed for both residential and non-residential buildings [4, 10, 13]. Such surveys, however, do not capture the temporal variation of the experienced thermal comfort nor the close relation it has to the domestic activities performed and the appliances used.

To address these shortcomings, thermal comfort has been the focus of interdisciplinary studies, for example the intersection between energy systems engineering and social sciences such as sociology $[2,14,15,21]$ and human geography [3]. These studies show how interlaced social activities and technical systems are, and stress the importance of different domestic activities and their variations between individuals/households in achieving thermal comfort. Thermal comfort is seldom the prime goal of individuals' activities but is included in activities and practices to fulfil goals in daily life, such as recovering from work by relaxing on the sofa $[8,28]$. Following this stream of thought, our research attention should be directed towards questions on how, where and when. Theoretical inspiration could be found in research approaches derived from time-geography [8] and social practice theory [28].

Our current research derives from the time-geographical approach and studies of everyday life [6]. Time-geography, while initially motivated by the study of human migration patterns [18], it quickly grew to become a mode of thinking for understanding change processes in society [7]. The reason behind this is that nothing happens in isolation, in order to understand human movement it is important to study and understand the activities and conditions that motivate their movements, i.e. the activity of individuals at the "stations". In this context, Ellegård [6] introduced the time-geographic diary as an effective approach to study individuals' everyday life through the activities they perform and the contexts (social, spatial, material) in which they are performed in. The time-geographic diary has been quite extensively used in social science studies of everyday life [1, 6, 17, 20, 22, 25, 29]. Bavaresco et al [1] assessed personal diaries in a review of different qualitative methods to collect data about human dimensions on energy use in buildings. The pros were listed as: getting data at the time of the event and as an effect minimising "retrospective bias"; collection of data could be done at the same time in different places since the collection is not depending on researchers presence; it involves occupants directly and could increase their awareness of thermal comfort and its connection to everyday life activities. Among the cons were: risks of incorrect filled out diaries or blank responses since researchers have little control over the respondents way of keeping the diary; participants might find the exercise of filling out the diary several times per day boring or interfering with other preferred or necessary daily activities in their lives; and in the case of diaries filled out on papers, the large amount of data might be difficult for the researcher to digitalise, code and analyse. In the present study, these concerns were discussed before methods were decided on and data collection commenced and the methodological issues will be presented in the next sections of this paper.

In our work we propose the use of visualization as an effective and flexible analysis tool for analysing perceived thermal comfort data collected through time-geographic diaries. Visualization has been an integral part of time-geography from its beginning. [16] The most well-known constructs of the time-geographical notation system are the 'space-time path' depicting an individual's spatiotemporal trajectory and the 'space-time cube', a three dimensional environment composed of a base map along the horizontal dimensions and time expanding in the vertical dimension. In the context of everyday life studies this strict spatial dimension has been replaced by an abstract activity space within which individuals 'move' between different activities spheres (activity types) building up 'individual paths'. An individual's individual path is thus the sequence of activities they perform over the course of the day. With this as a starting point, researchers in time-geography have teamed up with researchers in visualization research to develop methods to collect, communicate and visually analyse such time-geographic activity data describing everyday life, resulting in a visual analysis tool named VISUAL-TimePAcTS [9, 31].

\section{DATA COLLECTION}

This study is a total population sample comprising all residents formally registered in a Vallasstaden passive house, which over the period of study (June 2020-February 2021) were between 215 and 233 individuals. We collected data in the form of handwritten activity time-diaries to get information about all the activities individuals perform at home and their perceived thermal comfort while performing them. A diary template was created and printed as booklets. The inquired diary posts were: time of day, performed activity, electric appliance used (if any), location (room in the apartment/house) where the activity was performed, together with whom the it is 

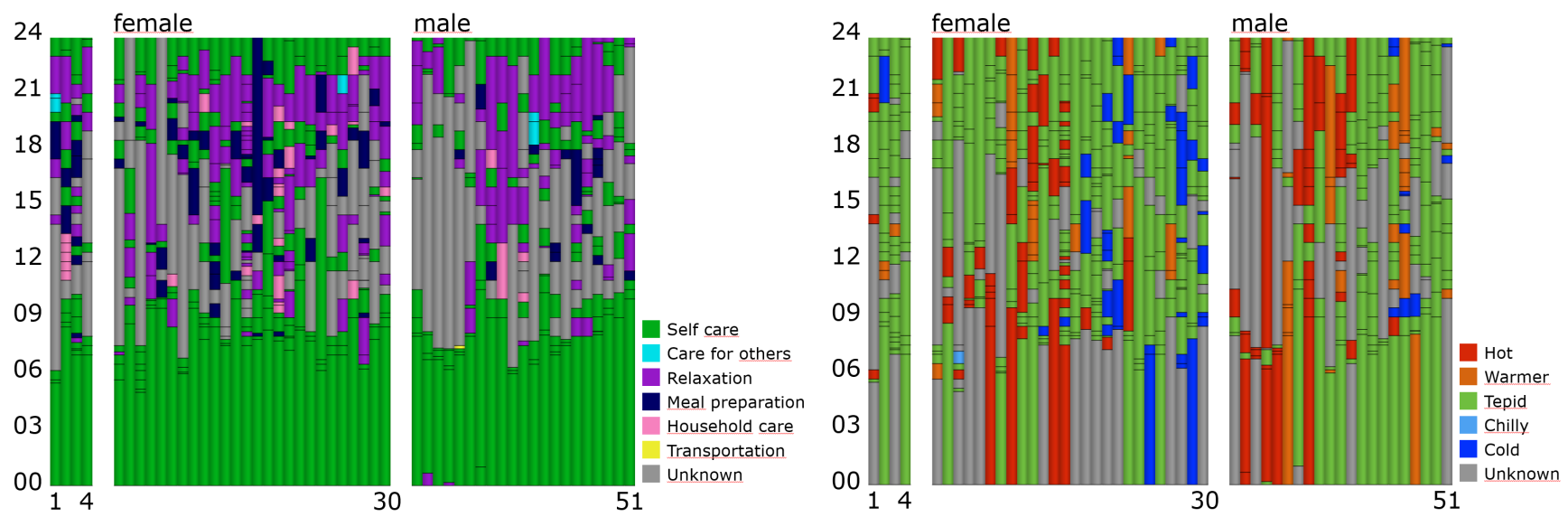

Figure 1: Activity diary visualization in VISUAL-TimePAcTS. Diaries are sorted by sex and date along the $x$-axis. Colour is used to display attributes associated with the performed activities, activity type to the left and thermal comfort to the right.

performed, perceived thermal comfort while performing it, and intervention action to address it. Activities performed outside the home were not part of our study and respondents were advised not to report these. The reason for choosing a handwritten diary approach was primarily related to privacy issues and to accessibility. As domestic activities can be sensitive information we did not want to assume that individuals would be comfortable sharing their information online. Regarding accessibility, since we aimed to reach a very specific user group for our study (Vallastaden passive house residents) the most straightforward approach was to reach them through their postal addresses.

So far in the project, we have collected a total of 51 diaries in three cycles based on season: summer, autumn and winter. During the summer period (June-August) 21 individuals submitted diaries, 4 individuals in the autumn (October) and 21 individuals during the winter period (November-February). In the autumn we only approached one family with diaries, since we didn't want to put the winter data collection to risk due to respondents' fatigue in taking part in this study. There was overlap of participants between periods and individuals submitted between 1-3 diaries. In total the collected dataset includes 21 diaries submitted from 13 male respondents aged 18-55, 26 diaries submitted by 18 female respondents aged 18-45, and 4 diaries from unknown respondents.

\section{VISUALIZATION OF THERMAL COMFORT}

Our aim with the study has been to explore and understand the timing and conditions of Vallastadens residents' perceived thermal comfort beyond summarising descriptive statistics. So we chose to represent and visually explore the collected thermal comfort data in the context in which they appear; i.e. in relation to the individuals' sequence of performed activities over the course of the day.

We adapted the previously developed visual analysis tool VISUALTimePAcTS for the purpose of our study [9,31]. VISUAL-TimePAcTS is a visual analysis tool that allows a user to represent and interactively explore individuals' time-diaries. The central representation used within VISUAL-TimePAcTS is the individual path, inspired by the time-geographical approach and notation [16], which corresponds to the sequence of performed activities over a day (24 hours), i.e. a single diary. Each diary is displayed as a segmented coloured band within a coordinate system where bands are sorted along the $\mathrm{x}$-axis, time is represented on the $\mathrm{y}$-axis, and each band segment corresponds to an activity (Fig. 1). Hence, each band in the representation corresponds to a single diary. The position and extent of each segment along the y-axis corresponds to the start time and duration of an activity respectively. The width of the bands is proportional to the size of the screen and the number of bands displayed simultaneously. By default, colour is used to represent the distinct type (category) of each activity (Fig. 1, left), but available surrounding attributes (e.g. location, appliance used) providing additional information concerning the activities can also be displayed in a similar manner. For this work, VISUAL-TimePAcTS was extended to include also thermal comfort as an analysis variable. Figure 1 (right) displays the same data but in this case representing the perceived thermal comfort of each performed activity. The individuals' diaries can be sorted by the user along the $\mathrm{x}$-axis with respect to up to two of the available background variables characterising each diary, such as diary date, individual age and sex. For example, in Figure 1 diaries are sorted by sex and date into unknown, female, and male and within each group by diary date (summer to winter). If two diaries have the same sorting values, then the unique numeric identifier of each diary is used as a tertiary sorting variable so that diaries will not overlap in the representation. Diaries can also be filtered by all available data attributes and selections can be made for highlighting and cross-comparisons allowing for flexible exploration of the data from different aspects.

In addition to the diary representation, frequency distribution graphs of selected activities can be drawn in order to closely study the temporal distribution of the activities, with respect to activity type or a surrounding attribute, such as perceived thermal comfort (Figures 2(B, D)), across a larger number of diaries. Finally, VISUALTimePAcTS includes also a number of methods for visual pattern mining which is however out of the scope of the present work [31]. 

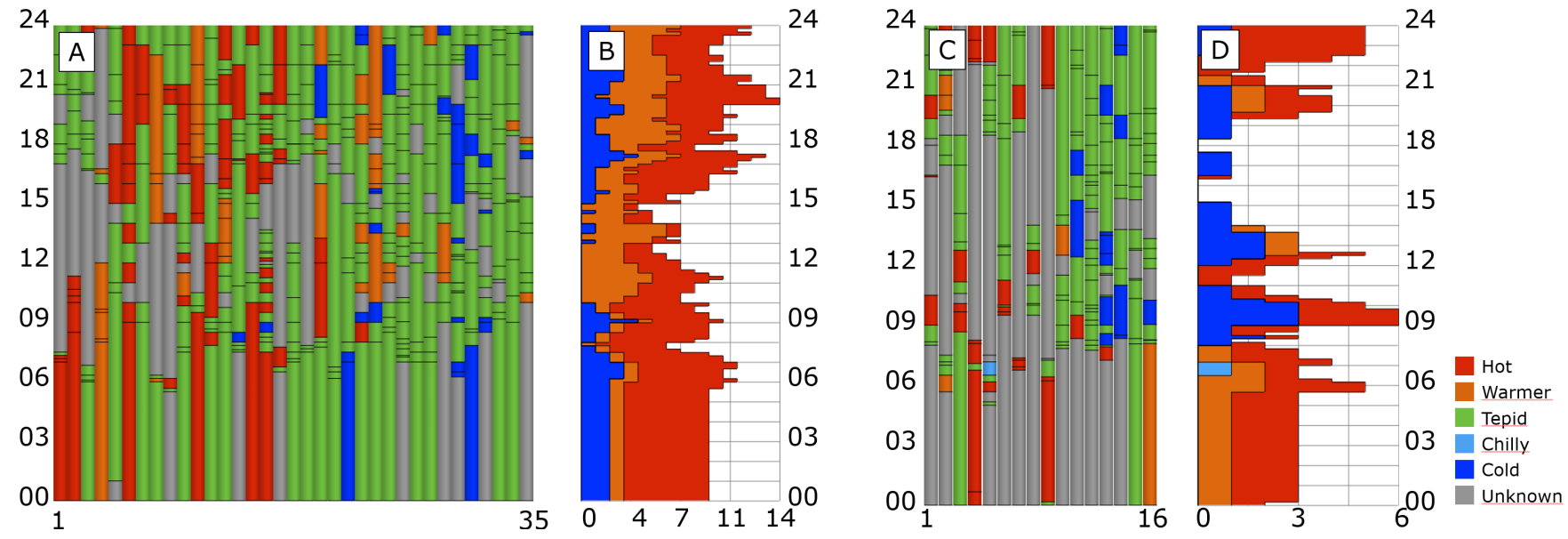

Figure 2: Visualization of perceived individual thermal comfort in passive houses $(C, D)$ and houses with other energy classes $(A, B)$. The diaries are shown in the in-context diary representation sorted by diary date (A, C) and the frequency distribution graphs of activities associated with hot, warmer, chilly and cold thermal comfort are shown adjacent (B, D).

\section{USE CASE}

To underline the richness of information available in diary data and the benefit of applying a visual exploration approach over the standard descriptive statistics approach, we present a visualization example of the collected data. Due to the low number of collected diaries we abstain from making any certain conclusions but we describe what is visible in the data.

Figures 2 (A, C) show the diaries of individuals in houses with other energy classes and passive classed houses respectively sorted by diary date; so summer months are displayed to the left and winter ones to the right in each diary representation. Figures 2 (B, D) display the respective frequency distribution graphs of the data subsets which offer a view into the temporal density distribution of thermal comfort categories over the course of the day. Looking at the representations, the residents of passive houses state they feel hot and warmer in terms of thermal comfort primarily in the morning and late evening hours during the summer months while they display cold thermal comfort throughout they day and not during night. In the other energy class houses hot and warmer thermal comfort is more evenly spread across the day while cold thermal comfort does not appear during midday.

\section{CONCLUSIONS AND DISCUSSION}

In this paper we propose the use of personal diaries, as an informationrich data source, in combination with an interactive visual analysis approach for the study of thermal comfort. We have shortly presented the diary study we performed in the new display city district Vallastaden, and have shown examples of how thermal comfort data can be represented and analysed in the context in which they appear. While studying thermal comfort through collection and visualization of diary data can offer a deeper understanding of the contextual conditions in which such comfort is experienced in terms of activity and timing it does come with a number of challenges.
Handwritten diaries are a time consuming process which requires the respondent to be willing to engage to a certain extent. To do that the respondents need to see the benefit (for them). Considering that the Vallastaden district is a new ambitious project towards more sustainable living, we expected that residents would be curious and interested to participate in a research project that was focusing on their well-being. While we did have some enthusiastic respondents, the response rate did not match our expectations. This unfortunately is the case with time-diary surveys in general.

We considered a number of alternative approaches for collecting similar information, each with their limitations, before we decided to proceed with the described diary approach. These included using a mobile app for data collection, however, this would imply that respondents would need to feel comfortable with sharing their data online and would need additional consents and ethics approvals. We considered pinging residents to inquire about their current perceived thermal comfort, this would however provide scattered data without continuity and context. Another approach would be to only perform interviews with residents and ask them to report on their overall experienced thermal comfort or to recollect the activities and perceived comfort of the day. If, however, responses are not logged continuously during the course of the day, the risk of less accurate reporting increases.

Despite these challenges, we believe that the proposed combination of personal diary data and visualization offers a powerful method to understand thermal comfort in private spheres and communicate it in a manner that also the responding residents can relate to and identify with.

\section{ACKNOWLEDGMENTS}

This work was supported by the Swedish Energy Agency and part of the research program Humans, energy systems and society, project number 46229-1. 


\section{REFERENCES}

[1] Mateus V Bavaresco, Simona D’Oca, Enedir Ghisi, and Roberto Lamberts. 2020. Methods used in social sciences that suit energy research: A literature review on qualitative methods to assess the human dimension of energy use in buildings. Energy and Buildings 209 (2020), 109702. https://doi.org/10.1016/j.enbuild.2019. 109702

[2] Camilla Brunsgaard, Mary-Ann Knudstrup, and Per Heiselberg. 2012. Occupant experience of everyday life in some of the first passive houses in Denmark. Housing, Theory and Society 29, 3 (2012), 223-254. https://doi.org/10.1080/ 14036096.2011.602718

[3] Jakob Carlander, Kristina Trygg, and Bahram Moshfegh. 2019. Integration of measurements and time diaries as complementary measures to improve resolution of BES. Energies 12, 11 (2019), 2072. https://doi.org/10.3390/en12112072

[4] Richard J De Dear. 1998. A global database of thermal comfort field experiments. ASHRAE transactions 104 (1998), 1141

[5] Richard J de Dear, Takashi Akimoto, Edward A Arens, Gail Brager, Christhina Candido, KWD Cheong, B Li, N Nishihara, SC Sekhar, S Tanabe, et al. 2013. Progress in thermal comfort research over the last twenty years. Indoor air 23, 6 (2013), 442-461.

[6] Kajsa Ellegård. 1999. A time-geographical approach to the study of everyday life of individuals-a challenge of complexity. Geofournal 48, 3 (1999), 167-175.

[7] Kajsa Ellegård. 2019. Time geography in the global context: An anthology. Routledge.

[8] Kajsa Ellegård and Jenny Palm. 2011. Visualizing energy consumption activities as a tool for making everyday life more sustainable. Applied Energy 88, 5 (2011), 1920-1926.

[9] Kajsa Ellegård and Katerina Vrotsou. 2006. Capturing patterns of everyday life presentation of the visualization method VISUAL-TimePAcTS. In IATUR - XXVIII Annual Conference, Copenhagen, Denmark. In 28th Conference of International Association for Time Use Research. Copenhagen, Denmark.

[10] Kristian Fabbri. 2015. Assessment of the influence of the thermal environmen using subjective judgement scales. In Indoor Thermal Comfort Perception. Springer 127-147.

[11] Wolfgang Feist, Jürgen Schnieders, Viktor Dorer, and Anne Haas. 2005. Reinventing air heating: Convenient and comfortable within the frame of the Passive House concept. Energy and buildings 37, 11 (2005), 1186-1203.

[12] Wiktoria Glad. 2006. Activities for passive houses: the transformation of an innovation in building processes for low energy housing. Doctoral thesis. Linköping Studies in Arts and Sciences. Dissertations No. 367. Linköping University.

[13] Lindsay T Graham, Thomas Parkinson, and Stefano Schiavon. 2021. Lessons learned from 20 years of CBE's occupant surveys. Buildings and Cities 2, 1 (2021).

[14] Kirsten Gram-Hanssen. 2010. Residential heat comfort practices: understandin users. Building Research \& Information 38, 2 (2010), 175-186. https://doi.org/10 1080/09613210903541527

[15] S. Guy and E. Shove. 2000. The Sociology of Energy, Buildings and the Environment: Constructing Knowledge, Designing Practice. Routledge. https://doi.org/10.4324/ 9781315812373

[16] Torsten Hägerstrand. 1970. What about people in regional science? Papers in Regional Science 24, 1 (1970)

[17] Carolina Hiller. 2015. Factors influencing residents' energy use-A study of energy-related behaviour in 57 Swedish homes. Energy and buildings 87 (2015), 243-252. https://doi.org/10.1016/j.enbuild.2014.11.013

[18] Torsten Hägerstrand. 1951. Migration and the growth of culture regions. In Studies in rural-urban interaction, Edgar Kant (Ed.). Lund: Royal University of Lund, 33--36.

[19] Charlotta Isaksson. 2009. Sustainable learning about indoor heating? Domesticating energy technology in passive houses. Ph.D. Dissertation. Linköping UniversityLinköping University, Technology and Social Change, Faculty of Arts and Sciences.

[20] Charlotta Isaksson and Kajsa Ellegård. 2015. Dividing or sharing? A timegeographical examination of eating, labour, and energy consumption in Sweden. Energy Research \& Social Science 10 (2015), 180-191. https://doi.org/10.1016/j. erss.2015.06.014

[21] Charlotta Isaksson and Fredrik Karlsson. 2006. Indoor climate in low-energy houses-an interdisciplinary investigation. Building and Environment 41, 12 (2006), 1678-1690. https://doi.org/10.1016/j.buildenv.2005.06.022

[22] Helena Köhler. 2017. Individual metering and debiting (IMD) in Sweden: A qualitative long-term follow-up study of householders' water-use routines. Energy Policy 108 (2017), 344-354. https://doi.org/10.1016/j.enpol.2017.06.005

[23] Dongyang Liang, Lei Yang, Xiang Cheng, and Gaoju Song. 2020. The Visualization Study on Research Progress of Thermal Comfort for Indoor Environment Based on CiteSpace. In IOP Conference Series: Earth and Environmental Science, Vol. 514 IOP Publishing, 032033.

[24] Veronika Földváry Ličina, Toby Cheung, Hui Zhang, Richard De Dear, Thomas Parkinson, Edward Arens, Chungyoon Chun, Stefano Schiavon, Maohui Luo, Gail Brager, et al. 2018. Development of the ASHRAE global thermal comfort database II. Building and Environment 142 (2018), 502-512.
[25] Jenny Palm, Kajsa Ellegård, and Mattias Hellgren. 2018. A cluster analysis of energy-consuming activities in everyday life. Building Research \& Information 46, 1 (2018), 99-113. https://doi.org/10.1080/09613218.2017.1302225

[26] Stefano Schiavon, Tyler Hoyt, and Alberto Piccioli. 2014. Web application for thermal comfort visualization and calculation according to ASHRAE Standard 55. In Building Simulation, Vol. 7. Springer, 321-334.

27] Jürgen Schnieders and Andreas Hermelink. 2006. CEPHEUS results: measurements and occupants' satisfaction provide evidence for Passive Houses being an option for sustainable building. Energy Policy 34, 2 (2006), 151-171. https://doi.org/10.1016/j.enpol.2004.08.049

[28] EA Shove. 2003. Comfort, Cleanliness and Convenience: The Social Organization of Normality. Berg.

[29] Jamie EL Spinney, K Bruce Newbold, Darren M Scott, Brenda Vrkljan, and Amanda Grenier. 2020. The impact of driving status on out-of-home and social activity engagement among older Canadians. Journal of transport geography 85 (2020), 102698. https://doi.org/10.1016/j.jtrangeo.2020.102698

[30] Federico Tartarini, Stefano Schiavon, Toby Cheung, and Tyler Hoyt. 2020. CBE Thermal Comfort Tool: Online tool for thermal comfort calculations and visualizations. SoftwareX 12 (2020), 100563. https://doi.org/10.1016/j.softx.2020.100563

[31] Katerina Vrotsou. 2010. Everyday mining: Exploring sequences in event-based data. Doctoral thesis. Linköping Studies in Science and Technology. Dissertations No. 1331. Linköping University. http://urn.kb.se/resolve?urn=urn:nbn:se:liu:diva58311 